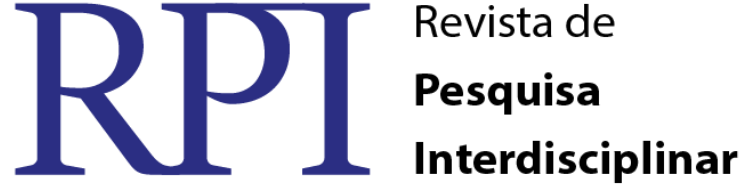

\section{REPRESENTAÇÕES SOCIAIS: VALORES E ENFRENTAMENTOS NA FORMAÇÃO CONTINUADA DO MESTRADO PROFISSIONAL}

\author{
Eliara Adelino da Silva-USS ${ }^{1}$ \\ Cristina Novikoff - UFCG ${ }^{2}$ \\ Felipe da Silva Triani - FGS ${ }^{3}$
}

\begin{abstract}
RESUMO
O estudo discute acerca da formação de professores para o ensino das ciências da saúde em nível de Mestrado Profissional. Devido a curta existência de Programas de Mestrados Profissionais (1997), existem problemas de diferente natureza (RIBEIRO, 2005) que carecem de aprofundamento, como a pouca experiência dos professores na atividade de ensino-aprendizagem de modo interdisciplinar. Parte-se do pressuposto teórico que para superar a dificuldade nessa formação tanto nos aspectos legais quanto nos conceituais, os mestrandos devem adentrar em temas variados para discutir os projetos de estudos e elaborar modos de intervenção. Assim, a formação deve permitir a vivência de duas experiências: pensar holisticamente e interdisciplinarmente para agir transdisciplinarmente. Diante deste contexto problematizado intenta-se estudar profundamente as tendências dessa formação questionando: Quais são as representações sociais de formação continuada para professores que estão se qualificando em Cursos de Mestrados Profissionais? Como esses professores compreendem a própria formação? Quais os enfrentamentos e apoios eles estão adotando? Objetiva-se discutir as representações sociais de formação continuada para professores em formação em Programas de Mestrados Profissionais. A partir dessas representações discutir-se-ão formas de enfrentamento, analisando seus apoios psicossociais e as implicações sócio afetivas dos mestrandos em formação para o ensino das ciências da saúde nos mestrados profissionais. Para o estudo adotar-se-á o referencial teórico da Teoria das Representações Sociais de Moscovici $(1978$; 2003) e a interpretação críticoanalítica de Duarte (2001). Trata-se de uma pesquisa qualitativa baseada na Etnografia de Erickson (2009). Os caminhos metodológicos percorrem as dimensões Novikoff (2010). Nota-se, assim o valor para o ensino onde os sujeitos falam, refletem e intervém no processo em estudo (GATTI, 2003).
\end{abstract}

Palavras-chave: Formação de Professores, Enfrentamento, Mestrado Profissional.

\section{SOCIAL REPRESENTATIONS: VALUES AND FACES IN THE CONTINUED TRAINING OF THE PROFESSIONAL MASTER}

\begin{abstract}
The study discusses about the training of teachers for the teaching of health sciences at Masters level professional. Due to the short existence of professional master's programs (1997), there are problems of different nature (Ribeiro, 2005) that further work is necessary, as little experience of teachers in the teaching-learning activity in an interdisciplinary way. We depart from the theoretical assumption that to overcome the difficulty in this formation in both the conceptual and legal aspects, the students must go into different themes to discuss the draft study and develop methods of intervention. Thus, the training must include the experience of two experiments: an interdisciplinary think holistically and to act transdisciplinary. Given this context problematized attempts to study in detail the trends of the
\end{abstract}

\footnotetext{
${ }^{1}$ Universidade Severino Sombra- RJ/ Fundação Dom André Arco Verde-RJ

${ }^{2}$ Universidade Federal de Campinas Grande

${ }^{3}$ Departamento de Educação Física da faculdade Gama e Souza
} 
training asking: What are the social representations of continuous training for teachers who are qualifying in Masters courses Professional? Because these teachers understand their formation? What the fighting and support they are taking? It aims to discuss the social representations of continuous training for teachers in training as a professional Master's program. From these representations will be discussing their ways of coping, psychosocial support and analyzing their implications for socioaffective masters in professional training in the Masters. For the study will adopt the theoretical framework of Social Representation Theory of Moscovici (1978, 2003) and critical-analytical interpretation of Duarte (2001). This is a qualitative research based on ethnography of Erickson (2009). The methodological paths traverse the dimensions Novikoff (2010). It was noted, so the value for teaching subjects where they talk, reflect and intervene in the process under study (GATTI 2003).

Keywords: Teacher Education, Coping, Professional Master

\section{INTRODUÇÃO}

O artigo apresenta importante estudo sobre escolhas para formação continuada em emstrados interdisciplinares. Muitos dos estudantes são profissionais em ação, com curto tempo de estudo e sem condições de parar de trabalhar. Buscam cursos pragmáticos que possam ajudar a pensar os problemas da vida profissional.

Para garantia de um mínimo de discussão, a proposta desse artigo é apresentar um recorte do estudo de mestrado profissional desenvolvido sob a orientação da metodologia proposta por Novikoff (2010) com perspectiva de apresentar algumas formas de enfrentamento diante das exigências na formação deste professor, principalmente nas instituições de ensino privado. Estas observações alimentaram o espírito de pesquisa e o interesse desta, em ampliar os estudos no campo do ensino das ciências da saúde, que traz como objeto as representações sociais, para analisar nessas, os valores e enfrentamentos apreendidos no processo de formação continuada em dois programas de mestrado profissional.

Duarte (2001), j demonstrou que o lema neoliberal "aprender a aprender" e as aproximações imaginárias deste com a teoria vigotskiana, tornou-se possível identificar alguns conceitos que configuram as representações sociais e que estão atreladas à formação docente, carecendo de crítica as teorias e práticas pedagógicas vigentes.

Diante deste cenário questionou-se.

RPI Revista de Pesquisa Interdisciplinar, Cajazeiras, v. 1, Ed. Especial, 444 - 470, set/dez. de 2016. 
Como os mestrandos compreendiam a formação no mestrado profissional? Como os mestrandos enfrentavam sua formação? Quais os apoios que os mestrandos buscavam para o enfrentamento? Quais as formas de valorização e enfrentamento psicossociais que os mestrandos vinham construindo?

Portanto, objetivou-se discutir as representações sociais de formação continuada para professores em formação em programas de mestrados profissionais. A partir dessas representações discutiram-se as formas de enfrentamento desses professores, seus apoios psicossociais e as implicações sócio-afetivas dos mestrandos das instituições de Ensino Superior privada, no Estado do Rio de Janeiro.

Assim, perspectivou-se contribuir com/para o processo dessa formação buscando a teoria das representações sociais como estratégia de avaliação diagnóstica aplicada ao ensino das ciências da saúde.

Para o estudo adotou-se o referencial teórico da Teoria das Representações Sociais de Moscovici (1978; 2003) e na interpretação crítico-analítica de Duarte (2001).

A pesquisa considerou que os aspectos psicossociais (VALA, 2004), inferem no fazer do homem, aqui, o pensar-fazer do professor. Noutras palavras, a subjetividade infere na atitude e cognição do sujeito.

A definição do objeto de estudo, sua problematização e definição dos objetivos, remeteu-me a abordagem qualitativa de pesquisa, de modalidade etnográfica de Erickson (1992), baseada na fenomenologia, numa perspectiva crítico-dialética. Os caminhos metodológicos percorreram as dimensões propostas por Novikoff (2010).

Notou-se, assim o valor dos conhecimentos sobre a subjetividade dos mestrandos, via representações sociais e seus enfrentamentos para o ensino de ciências de saúde, em especial, para a formação de professores, onde os sujeitos são eles mesmos que falam, refletem e intervém no processo em estudo (GATTI, 2009). A dialética marcou a pesquisa e teve o potencial de sua intervenção para superar o vazio teórico em tempos "profissionalizantes".

Para delimitar o estudo da formação de professores, focou-se neste projeto a formação continuada e não a inicial. Em relação ao lugar desta formação elegeu-se o mestrado profissional e não o acadêmico. O primeiro por ser parte da vivência de formação da autora e é pouco estudado devido seu surgimento ser recente (1997).

RPI Revista de Pesquisa Interdisciplinar, Cajazeiras, v. 1, Ed. Especial, 444 - 470, set/dez. de 2016. 
Enfim, esclarece-se de inicio que não foi pretensão da autora esgotar o tema aqui descrito mais sim provocar novos espaços de discussões frente aos conhecimentos psicossociais na/para a formação de professores.

\section{Desenvolvimento da pesquisa}

Para o delineamento desta pesquisa, além da especificação de métodos e técnicas que foram aplicados, tornou-se necessário buscar informações junto aos sujeitos, cuja seleção teve como critérios iniciais para a inclusão e seleção dos sujeitos da pesquisa os interessados em participar. Foram levados em consideração àqueles que estavam no ano de 2010 e 2011 em formação continuada, no nível stricto sensu (Mestrado Profissional), independente da sua área de formação profissional.

Após esse primeiro contato convidaram-se 10 mestrandos de Mestrado Profissional em duas IES do estado do Rio de Janeiro, aonde foi realizada a pesquisa e, que nesse artigo denominaremos de IES A e de IES B.

Em relação aos aspectos éticos, este estudo foi desenvolvido respeitando as diretrizes estabelecidas na Resolução de 196/96 do Conselho Nacional de Saúde. (BRASIL, 1996).

Quanto aos instrumentos de coleta de dados, utilizou-se os desenvolvidos no Laboratório de estudos e pesquisas em representações sociais na/para formação de professores - Lageres/CNPq. São eles: questionário sócio-cultural , "Inventário de valorização e enfrentamento", de Antônio Cano Vindel e Juan José Miguel (adaptado por NOVIKOFF, 2006), e Dinâmica Curtograma (ANDRADE, 2010, p. 51) que adaptamos para levantar os conhecimentos e valores a partir do que os mestrandos gostam, curtem, portanto revelam sua afetividade com o pensar-fazer.

Os valores foram pautados no diagrama de Novikoff (2006). Esses correspondem a 5categorias, ou seja:

Segundo Novikoff (2006, p.147), os valores são delineados da seguinte forma:

- Valores sócio-relacionais. Indicam os conhecimentos das relações sociais. Incluem os conhecimentos sobre os sujeitos partícipes da instituição (alunos, professores, coordenadores), incluindo as questões éticas. Esta categoria aponta a racionalidade estético-expressiva ou crítico-reflexiva, no pensamento para o coletivo.

- Valores normativos. Evidenciam os conhecimentos técnicos e normativos. Estes valores se encontram na racionalidade moral-prática, com

RPI Revista de Pesquisa Interdisciplinar, Cajazeiras, v. 1, Ed. Especial, 444 - 470, set/dez. de 2016. 
relação aos direitos, e no pensamento crítico-reflexivo, para as normas legais.

- Valores identitários. Caracterizam os conhecimentos sobre as emoções, bem como a imagem de si e do outro. Demonstram os valores éticos espirituais e técnicos. Estes valores se encontram na racionalidade estético-expressiva ou crítico-reflexiva, no pensamento para o eu e o outro, como se fossem os mesmos.

- Valores gnosiológico-pedagógicos. Incluem os conhecimentos sobre os aspectos didático e pedagógico, inventariando as questões de ordem de exigências técnicas e acadêmica para o fazer docente. Esta categoria aponta a racionalidade moral-prática, no pensamento do fazer pedagógico.

- Valores sócio-profissionais. Indicam os conhecimentos das condições de trabalho. Refletem os objetos materiais ligados ao consumo/utilidade e econômicos. Estes dizem da racionalidade técnico-instrumental.

Segundo a pesquisadora, os valores

[...] interagem entre si e têm como centro originário as representações sociais que em seu processo de objetivação apresentam o conhecimento sobre as diferentes questões e a ancoragem denota o sentido dado a este conhecimento. (NOVIKOFF, 2006).

É importante entender a valoração para entender o enfrentamento, pois os valores que uma pessoa tem sobre si própria e sobre o mundo direciona sua motivação, seu compromisso, seu envolvimento com as diversas situações de sua vida.

\section{Alguns resultados}

As respostas dos mestrandos, após triagem das questões, tanto da IES A como da IES B foram organizadas, agrupando-as, de acordo com a categorização de valores são ilustradas no gráfico 1 .

Gráfico 1: Categorização de Valores

RPI Revista de Pesquisa Interdisciplinar, Cajazeiras, v. 1, Ed. Especial, 444 - 470, set/dez. de 2016. 


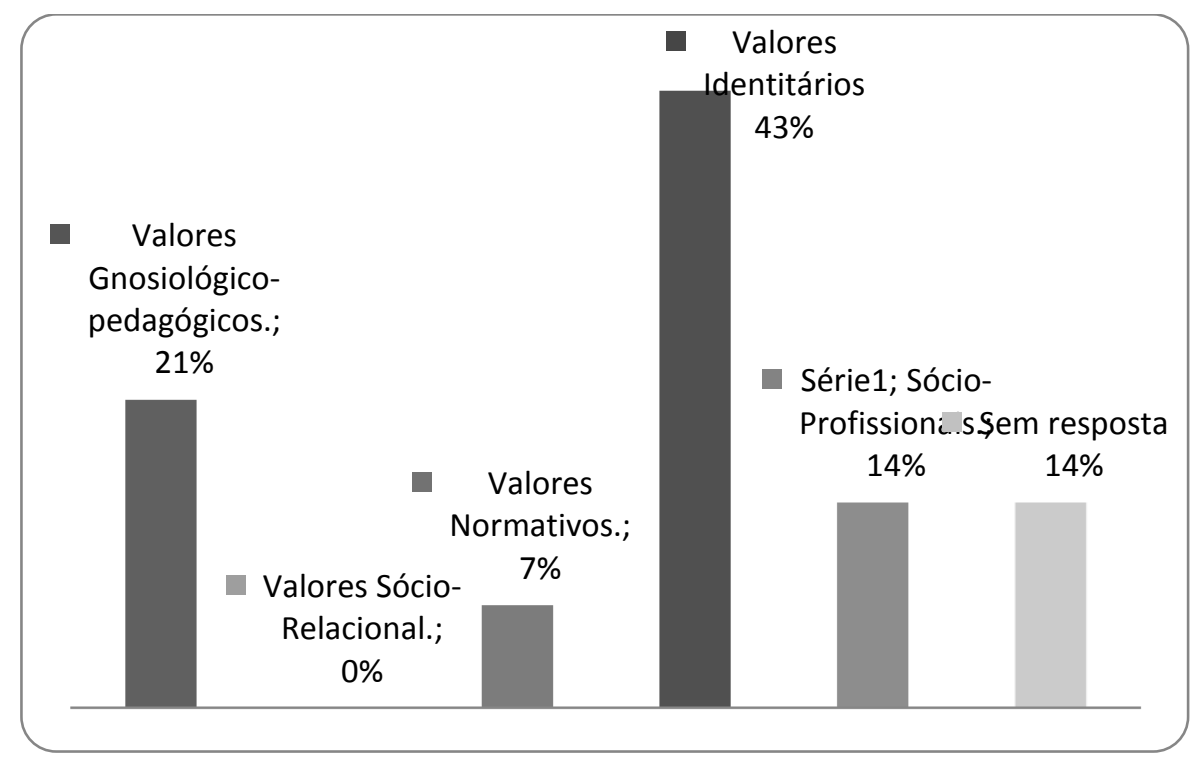

Em relação as questões afetas aos valores que os mestrandos consideravam importantes no Mestrado Profissional as narrativas apontam para valores distintos, como se pode observar nos exemplos a seguir.

Os valores identitários encontrados nos $43 \%$ dos entrevistados caracterizaram os aspectos relacionados com as emoções, a imagem de si e do outro e demonstraram os valores ético, espirituais e técnicos.

. “Disciplina, disponibilidade, companheirismo, acreditar"M1

..."Determinação, superação”.M2

..."Envolvimento, Engajamento"M3.

... “Perseverança, compromisso, empenho.”M8

Estes valores basearam-se na racionalidade estético-expressiva ou crítico-reflexivo, no pensamento para o eu e o outro, como de fossem os mesmos.

Os mestrandos utilizaram as palavras que consideravam mais importantes para o mestrado profissional, sendo estas descritas como, companheirismo, acreditar, disponibilidade, determinação, superação, envolvimento, engajamento, perseverança, compromisso, empenho, compreensão, humildade, valores afetivos e profissionais, e moral.

As respostas proferidas por estes, indicaram os sentimentos e pensamentos, que foram os basilares para sua estrutura individual e social, ancorados nas relações de amizade, RPI Revista de Pesquisa Interdisciplinar, Cajazeiras, v. 1, Ed. Especial, 444 - 470, set/dez. de 2016. 
aspectos automotivacionais, dentre estes perseverança, superação e responsabilidade, tempo perpassando pelas questões éticas e afetivas, dentro das relações sociais.

Os valores gnosológicos-pedagógicos, foram referentes aos 21\%:dos entrevistados. Este grupo referiu-se as disciplinas, capacitação docente, orientação adequada, disponibilidade dos orientadores, aulas bem dadas, discussão de artigos, melhora do ensino aprendizagem, produto coerente com o meio que seria aplicado, temas das aulas ministradas.

Os valores descritos acima reportaram para os aspectos didáticos e pedagógicos, sendo estes voltados para a racionalidade moral-prática, no pensamento do fazer pedagógico.

Nos valores sócio-profissionais, normativos foram encontrados nos 7\% das respostas, juntamente com os que não ofereceram nenhum tipo de informação, e $0 \%$ que ficaram com os valores sócio-relacionais.

..."Produto coerente com o meio que será aplicado.” M5

“Orientação adequada, disponibilidade dos orientadores, adequação de horário.”M6

“Adequação dos temas as aulas ministradas, organização de horários.”M7

$\mathrm{Na}$ questão de busca de apoio para a realização de suas tarefas e/ou informações para cumprimento das mesmas o questionamento versou sobre a necessidade de existência de algum tipo de apoio para o aluno de mestrado.

Observa-se no gráfico 2 que os apoios necessários aos mestrandos para estarem inseridos no mestrado profissional é significativamente institucional, ou seja, currículo com flexibilidade de horário.

RPI Revista de Pesquisa Interdisciplinar, Cajazeiras, v. 1, Ed. Especial, 444 - 470, set/dez. de 2016. 


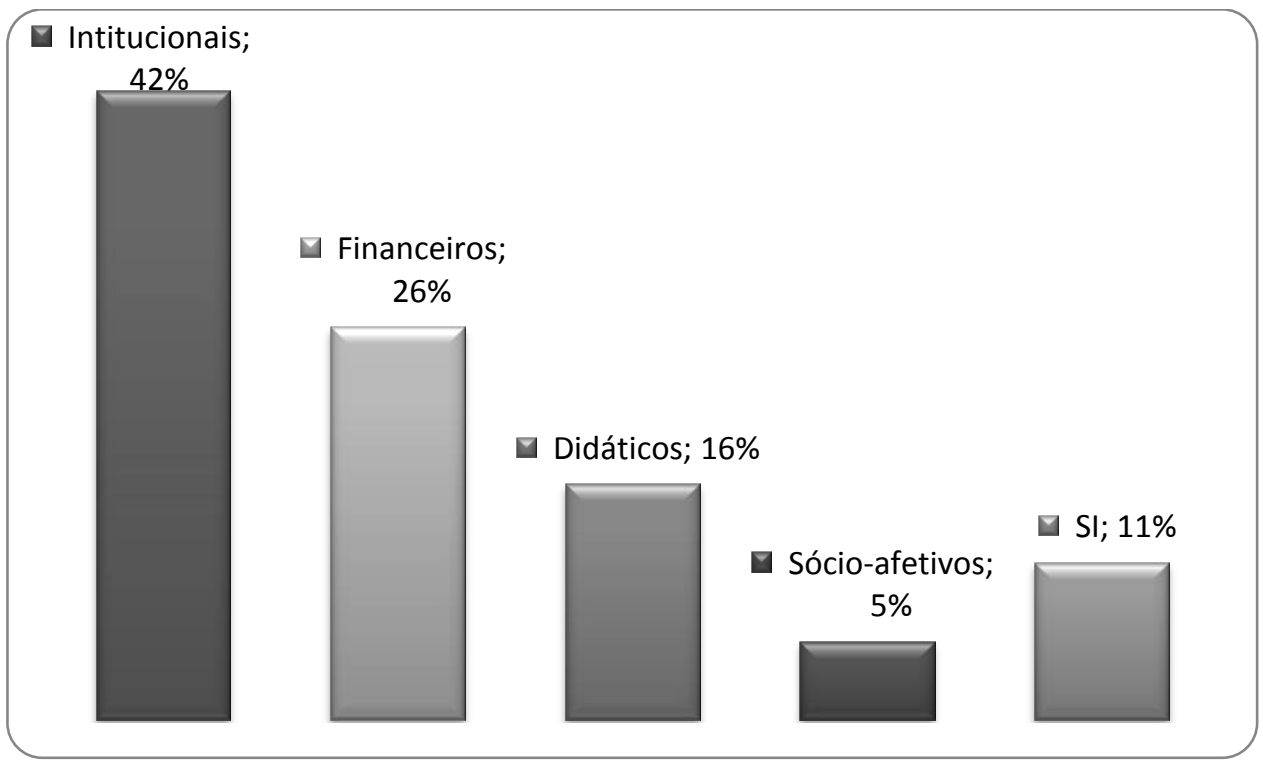

Fonte: Questionário socio-cultural da pesquisa

Gráfico 2: Apoios necessários aos mestrandos, segundo as respostas da questão relativa ao apoio no questionário sociocultural - 2011

O resultado apontou que $40 \%$ dos entrevistados, acreditavam na importância do apoio pedagógico, seguindo de $25 \%$ financeiro, $14 \%$ psicopedagógico $7 \%$ outro referenciado como orientador $14 \%$ e nenhum $0 \%$.

Apesar de o apoio institucional aparecer numericamente superior com $42 \%$ de representatividade, se limita a dispensa de carga horária. Já o apoio financeiro, com $26 \%$ de respostas apontou o baixo investimento no professor em formação. Impressionam, por igual o diminuído apoio didático com $16 \%$ de respostas. O menos vivenciado no mestrado foi o apoio sócio-afetivo (5\%). Por igual surgiu a zona muda revela o silêncio na escrita (11\%).

Observou-se nos resultados apresentados que, a opção pelo apoio pedagógico evidenciou, a necessidade de oferecer ao mestrando um aporte direcionado para as seu aprimoramento enquanto docente e pesquisador, o que veio reforçar a necessidade de uma maior inserção de estratégias de ensino-aprendizagem, afim de atender a demanda e as expectativas deste mestrando,sejam estas em relação a elaboração de seu produto, tese ou os conhecimentos necessários para sua formação profissional ou pesquisa.

O apoio financeiro veio em segundo lugar, embora tenha sido descrito na questão 8 (aqui não apresentada por necessidade de recorte textual), como um dos apoios que estes mais 
recebiam para estarem inseridos no mestrado profissional, este foi selecionado pelos sujeitos como o segundo mais escolhido para que o aluno pudesse estar inserido no mestrado.

Percebeu-se que as respostas dos mestrados ao apontarem o recurso financeiro, sinalizaram a necessidade de uma ajuda financeira, a fim de ajudar na sua formação, principalmente pelos custos referentes a participações de congressos, seminários, elaboração de projetos, pôsteres, viagens, aquisição de livros para fortalecimento do conhecimento entre outros, que são partes também primordiais para o bom desenvolvimento e articulação na Formação Continuada.

O apoio psicopedagógico foi pontuado por $25 \%$, esta abordagem, apontou para uma forma de auxilio, frente às dificuldades sócio-afetivas que possam surgir, bem como os enfrentamentos ao qual este terá de lidar.

Sem informação, foram descritos apenas por $14 \%$ dos entrevistados e nenhum $0 \%$.

Quanto aos critérios que foram adotados pelos mestrandos para a escolha do mestrado profissional os dados apontam para três itens, de acordo com o gráfico

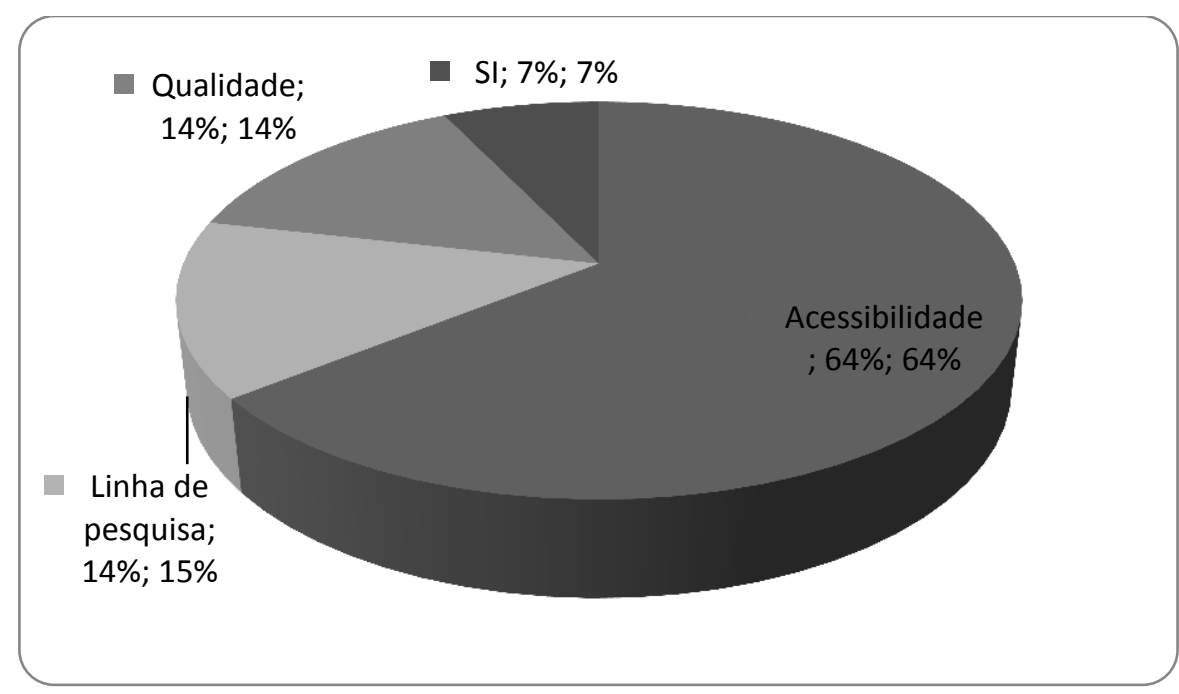

Gráfico 3: Critério da escolha do Mestrado Profissional

Quanto aos critérios que foram adotados pelos mestrandos para a escolha do mestrado profissional priorizou-se a elaboração de categorias para melhor visualização e entendimento (quadro 1)

RPI Revista de Pesquisa Interdisciplinar, Cajazeiras, v. 1, Ed. Especial, 444 - 470, set/dez. de 2016. 
Quadro1: Critérios de escolha do mestrado profissional

\begin{tabular}{|c|c|c|c|c|c|}
\hline Sujeitos & Respostas & : & 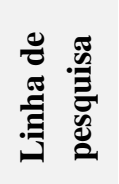 & 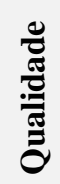 & $\mathbf{S} / \mathbf{I}$ \\
\hline M1 & $\begin{array}{l}\text { "1) Objetivos do curso profissional;2) Facilidade de } \\
\text { locomoção e 3) Presencial." }\end{array}$ & & & $\mathrm{X}$ & \\
\hline M2 & "Acessibilidade." & $\mathrm{X}$ & & & \\
\hline M3 & "Área de atuação, linha de pesquisa" & & $\mathrm{X}$ & & \\
\hline M4 & $\begin{array}{l}\text { "Este atenderia melhor a prática docente na qual estou } \\
\text { inserida de forma interventiva" }\end{array}$ & & $\mathrm{X}$ & & \\
\hline M5 & "Facilidade com adaptação, estudo e trabalho". & $\mathrm{X}$ & & & \\
\hline M6 & "Facilidade de acesso e horário compatível." & $\mathrm{X}$ & & & \\
\hline M7 & $\begin{array}{l}\text { "Facilidade de realização do mestrado e continuar o } \\
\text { trabalho" }\end{array}$ & $\mathrm{X}$ & & & \\
\hline M8 & $\begin{array}{l}\text { Horário da liberação do setor Público e a atividade e da } \\
\text { instituição de ensino }\end{array}$ & $X$ & & & \\
\hline M9 & "Localidade e acesso." & $\mathrm{X}$ & & & \\
\hline M10 & $\begin{array}{l}\text { "Necessidade de qualificação, fácil acesso ao local } \\
\text { (perto da residência, conhecimento." }\end{array}$ & $\mathrm{X}$ & & & \\
\hline M11 & "Perto da minha casa e linha de pesquisa." & $\mathrm{X}$ & & & \\
\hline M12 & $\begin{array}{l}\text { "Por ser na minha cidade, fácil acesso, por ser em } \\
\text { ensino de saúde (área que gosto, por ser em horário } \\
\text { compatível com o meu trabalho diário". }\end{array}$ & $\mathrm{X}$ & & & \\
\hline M13 & "Qualidade do curso (nota da CAPES), distância" & & & $\mathrm{X}$ & \\
\hline M14 & & & & & $\mathrm{X}$ \\
\hline
\end{tabular}

Referente aos aspectos negativos da vida do professor estudante de mestrado relacionado com categorização apontadas, foram citados:

A falta de tempo foi o que mais evidenciou nas respostas dos mestrandos, o que demonstrou a dificuldade de conciliar o trabalho e estudos, devido a falta de tempo, relacionado ao cansaço, as responsabilidades familiares, entre outros fatores. 
..."Pouco tempo para estudar,falta de tempo, gasto elevado, vida social prejudicada."M8 ..."Pouco tempo, o que faz deixar algo importante de escanteio."M11

Foram descritas ainda, algumas manias adquiridas ao logo da carreira, como fonte que também interfere de forma negativa na vida do mestrando, além da rotatividade de professores.

A M1 escreveu sobre o contexto familiar que ficou abalado, este relato apontou para as exigências e responsabilidades das mulheres junto ao lar, para com os filhos, o cônjuge, além da sobrecarga tripa da jornada de trabalho, necessitando despender maiores esforços para poder cumprir tanto as suas funções regulares de esposa, mãe quanto a de profissional e mestranda.

...“ Convivência familiar fica abalada."M1

A resposta do M3 levou-nos a análise de diversos fatores desencadeadores de vários enfrentamentos no mestrado, foi pontuado o estresse.

..."Estresse.”M3

Tal abordagem sinalizou para os relacionamentos com os colegas, o próprio relacionamento aluno-orientador e aluno-coordenação, a falta de motivação, articulação do tempo para realizar o mestrado, os aspectos financeiros da pesquisa e as finanças pessoais.

E ainda, as apresentações orais, o pouco contato com o orientador, as dificuldade na escolha do tema escolhido para a pesquisa, a expectativa de não atingir o resultado esperado pela banca, as cobranças externas para conclusão devido a bolsas, empregos e a solidão na produção de sua pesquisa, entre outros.

$\mathrm{Na}$ questão 24, foi perguntado aos mestrandos sobre as técnicas de ensino que este aprendeu e que utiliza em suas aulas, com seus devidos comentários. As respostas obtidas serviram para a elaboração das categorias listadas na tabela 8 , a seguir. 
Tabela 1: Percentual de técnicas de ensino que aprendeu e utiliza em suas aulas

\begin{tabular}{ccccc}
\hline Técnica & $\begin{array}{c}\text { Discussões e leitura } \\
\text { de artigos }\end{array}$ & Vídeos & Desconhece & Sem Informação \\
\hline Qtde & 10 & 1 & 1 & 2 \\
Percentual & $72 \%$ & $7 \%$ & $7 \%$ & $14 \%$ \\
\hline
\end{tabular}

Referente à discussão e leitura de artigos foram apontados por $72 \%$ a leitura de artigos, sem informação $14 \%$ vídeos foram pontuados por $7 \%$ e desconheciam também por $7 \%$ dos entrevistados .

Sobre as técnicas de ensino, respondidas pelos nos mestrandos conforme aponta o quadro 17, as discussões e leitura de artigos, foram as mais sobressaíram nas respostas com $72 \%$, como técnicas de ensino, que pudessem ser trabalhadas, para o processo ensino aprendizagem.

A questão 6, compõe-se dos valores normativos referiram-se ao como os mestrandos compreendiam o que seus colegas de turma, pensavam sobre o mestrado profissionalizante, suas normas e seus direitos. Apesar de discutir normas, aqui o olhar é sobre o que se pensa que o outro sabe.

As análises das respostas com uma visão positiva dos colegas frente aos conhecimentos destes em relação ao mestrado profissional, totalizaram $29 \%$ contra $57 \%$ dos que tem uma visão negativa.

..."Compreendo que muitos entenderam suas normas e as seguiram, também reivindicamos direitos em vários momentos".M5

..."Não tenho ideia do que eles pensam.”M7

...“O grupo conhece as normas e direitos.”M8

..."Penso que todos compreendem o que foi nos passado no início do curso.”M12

As repostas, de um modo geral, sinalizaram que seus colegas mestrandos pouco conheciam sobre o mestrado profissional e, também, permitiu-nos identificar a diversidade de RPI Revista de Pesquisa Interdisciplinar, Cajazeiras, v. 1, Ed. Especial, 444 - 470, set/dez. de 2016. 
graus de interesses que estiveram presentes na formação continuada, bem como a inserção de grupos bastante heterogêneos, com formações distintas e com significados variados para cada indivíduo específico.

Segundo os percentuais encontrados, $43 \%$ apontam que os outros colegas conhecem o Mestrado profissional; $21 \%$ indicam que valorizam somente a titulação e desconhecem os direitos e deveres do Mestrado Profissional; 7\% sugerem que desconhecem o que o outro pensa e os demais $7 \%$ ficam na zona muda. Cabe observar que as duas últimas categorias se aproximam, como visto no entendimento sobre zona muda ser uma escolha consciente de "velar" o conhecimento.

..."Acho que desconhecem os direitos e tem relativos conhecimentos das normas” M1

...“Acredito que uma pequena parte do grupo está ali apenas para alcançar o título de mestre, infelizmente.”M2 ...“Alguns estão apenas para receber o título e acrescentar mais no salário. Eu quero crescer profissionalmente.”M3

...“Compreendo que eles só pensam em direitos, pois quando tocam em deveres, logo se manifestam contra.”M4 ..."Dizem acreditar nessa proposta.”M6

..."Pelo que ouço, eles não se sentem inferiorizados por estar fazendo um Mestrado Profissional e são indiferentes quanto às normas e direitos.”M9

..."Pensam como um meio de conseguir titulação e aprimorar suas práticas."M10

..."Pensam que é mais simples, mais fácil que o acadêmico.”M11

Importa destacar que o valor que cada um dará a sua formação, irá variar de pessoa para pessoa, e que poderá estar relacionada para a promoção no trabalho, a melhor remuneração, status, a valorização profissional, estabilidade, entre outros fatores.

$\mathrm{Na}$ questão 25 foi solicitado que o mestrandos identificassem a tarefa que consideravam mais desagradável para realizar no mestrado.

Para melhor compreensão criou-se uma tabela com 3 categorias que segue abaixo e com seus respectivos valores.

Tabela 2: Percentual de atividades consideradas desagradáveis no Mestrado

\section{Profissional}

RPI Revista de Pesquisa Interdisciplinar, Cajazeiras, v. 1, Ed. Especial, 444 - 470, set/dez. de 2016. 


\begin{tabular}{ccc}
\hline Horário de Orientação & Método de Ensino & Sem informação \\
\hline $\mathbf{1}$ & 9 & 4 \\
$\mathbf{7 \%}$ & $64 \%$ & $29 \%$ \\
\hline
\end{tabular}

Os $64 \%$, foram relacionados ao método de ensino, que sugere, segundo resultado obtido, uma reavaliação, do método empregado.

\section{Análise do inventário de valoração e enfrentamento}

Utilizou-se como instrumento, o inventário de valoração e enfrentamento (IVA), de Figueroa e Marro (2002, p.53), pautado no inventário de valoração e enfrentamento de CanoVindel; Miguel-Tobal (1992), para identificar das estratégias de enfretamento, mais utilizadas pelos mestrandos dos Programas de Mestrado Profissional, em relação as exigências que excediam seus recursos, tanto na vida pessoal, quanto profissional e social.

O IVA (anexo 02), foi traduzido e adaptado a linguagem brasileira, por NOVIKOFF (2006).

Os participantes foram instruídos, a escreverem uma situação problemática que tivesse lhes tivesse afetando ou que ainda, continuava lhes afetando. As respostas obtidas no inventário, na primeira questão foram descritas no quadro abaixo, a partir da elaboração de 6 categorias, conforme tabela 16:

\section{Tabela 3 : Situação problemática}

\begin{tabular}{cccccc}
\hline $\begin{array}{c}\text { Falta de } \\
\text { tempo }\end{array}$ & $\begin{array}{c}\text { Perdas e } \\
\text { problemas } \\
\text { familiares }\end{array}$ & $\begin{array}{c}\text { Problemas no } \\
\text { trabalho e curso }\end{array}$ & Insegurança & $\begin{array}{c}\text { Prefere não } \\
\text { falar }\end{array}$ & Sem informação \\
\hline 2 & 4 & 3 & 1 & 2 & 2 \\
$14 \%$ & $30 \%$ & $21 \%$ & $7 \%$ & $14 \%$ & $14 \%$ \\
\hline
\end{tabular}

RPI Revista de Pesquisa Interdisciplinar, Cajazeiras, v. 1, Ed. Especial, 444 - 470, set/dez. de 2016. 
Os problemas e perdas familiares foram pontuados por $30 \%$ dos entrevistados, com o maior número percentual, das situações problemáticas, e que apontam para uma possível desestrutura em vários níveis, sejam tanto nos níveis sociais, emocionais e familiares, conforme quadro 25 .

Problemas no trabalho e no curso somaram $21 \%$ das situações problemáticas que estiveram afetando o mestrando entre eles os problemas aos relacionamentos no trabalho e as adaptações referentes as mudanças ocorridas na trajetória do curso e que foram descritos pelos mestrandos M6,M12 e M13.

A Falta de tempo foi pontuada pelos mestrandos 1 e 5, somando 14\% das respostas, as respostas que sinalizaram a rotatividade de atividades, as exigências necessárias para atender as demandas do mestrado, além das prioridades da vida familiar, social, e pouco tempo para descanso

Foram identificados $14 \%$ dos entrevistados que preferiram não falar e sem informação.

Os $14 \%$ identificados, na citação acima, sinalizam estratégias defensivas, onde o indivíduo, evita confrontar-se com a ameaça, não modificando a situação.

Negar o fato para si mesmo ou não levar em consideração o que as pessoas dizem ou fazem, pode ser uma das estratégias de enfrentamento. A insegurança foi respondida por $1 \%$ dos entrevistados.

O IVA teve a pretensão, identificar as estratégias de enfrentamentos que os mestrandos utilizavam para lidar com as situações estressantes, sendo a primeira parte deste instrumento destinada para a avaliação e a valoração da situação como ameaçadora (VSA).

Os $25 \%$, descreveram a situação muitas vezes ameaçadora, quase nunca ameaçadora, com 23\%, poucas vezes ameaçadora19\%, e com 17\%, quase sempre ameaçadora e umas vezes sim, outras, não ameaçadora, com $16 \%$ dos entrevistados.

A primeira parte do IVA avaliou, a valoração da situação como ameaçadora (VSA).

Sendo os $25 \%$, que descreveram a situação muitas vezes ameaçadora, tal análise sugere que o foco na situação, com o percentual de $25 \%$, que sinalizam a focalização no 
problema, como algo muito importante para a vida do mestrando, difícil de controlar e resolver.

A parte cinco do IVA, trouxe a avaliação da frequência com que os mestrandos utilizaram a avaliação centrada na emoção(ACE).Avaliação centrada na Emoção.

Tabela 4: Avaliação cognitiva centrada na emoção (ACE)

\begin{tabular}{|c|c|c|c|c|}
\hline \multicolumn{5}{|c|}{ AVALIAÇÃO CENTRADA NA EMOÇÃO } \\
\hline Quase nunca & Poucas vezes & $\begin{array}{c}\text { Umas vezes sim outras } \\
\text { vezes não }\end{array}$ & Muitas vezes & Quase sempre \\
\hline $8 \%$ & $17 \%$ & $20 \%$ & $26 \%$ & $29 \%$ \\
\hline
\end{tabular}

O resultado encontrado, na tabela descrita acima, sugeriu que os mestrandos ao invés de anular e afastar a situação, estressante de seu cotidiano, optam pela resolução dos problemas, através da modificação de suas atitudes, e inclusão de medidas que reduzam o nível de tensão focando em suas habilidades e qualidades para sentir-se mais seguro e capaz de lidar com as pressões do dia a dia e do ambiente ao seu redor.

Em relação às estratégias de enfrentamento que os mestrandos do Programa de Mestrado Profissional, adotaram após sua inserção no mestrado profissionalizante, foram o de recorrem a estratégias focadas na emoção, de forma passivas.

Quanto as estratégias de enfrentamento cognitivo e as condutas motoras foram dirigidas para reduzir a emoção, pouco fez- se para inferir e adotar uma atitude de autodeterminação, mais sim uma atitude passiva para as questões normativas e de direito (Apoio IES), e evitativa em relação às questões afetivo-relacionais.

Em relação a Conduta Motora Centrada na Emoção (ACME), diante dos conflitos ou estresses os mestrandos foram identificados a busca pelo autocontrole, seja este através do desvio da atenção, dos pensamentos, atitudes que os preocupavam, procurando eliminar, os pensamentos negativos, objetivando melhorar o seu estado de ânimo.

\section{Aplicação do Curtograma}

RPI Revista de Pesquisa Interdisciplinar, Cajazeiras, v. 1, Ed. Especial, 444 - 470, set/dez. de 2016. 
Pela busca de estratégias de planejamentos e reavaliação dos conhecimentos oferecidos nos mestrados profissionais, levou-se em consideração as sugestões apontadas pelos mestrandos e as experiências vivenciadas pelos mesmos, através da aplicação de uma Dinâmica, denominada "Curtograma", ( ANDRADE, 2010; Dinâmica Curtograma ,adaptada por SILVA, Eliara Adelino, 2010; Novikoff, Cristina 2010).

Esta dinâmica teve como intenção identificar as necessidades de mudanças na elaboração da prática pedagógica, desenvolvida no Mestrado Profissional e favorecer a reflexão do mestrando envolvido no programa de mestrado profissional, possibilitar o professor a rever o planejamento e as estratégias de ensino que estejam sendo aplicadas na prática pedagógica.

E ainda, buscou estimular a participação do mestrando, a fim de propiciar a este uma aprendizagem significativa, para o seu campo de atuação, permitindo-lhe a troca de diferentes saberes às realidades do grupo específico.

Algumas indagações serviram de ancoragem para a aplicação do Curtograma, para esta pesquisa.

A partir destes questionamentos foi aplicado a Dinâmica do Curtograma com 10 mestrandos, sendo 03 da IESA e 06 da IESB com os aspectos classificados como Curto e Gosto, Curtem e Não Fazem, Não Curte e Fazem, Não curto e Não fazem.

Através desta dinâmica foi possível identificar nas respostas dos mestrandos, os seus sentimentos e valores e identidades individuais, frente as atividades desenvolvidas no Mestrado Profissional, tornando assim um importante instrumento para a percepção dos valores e enfrentamentos dos participantes.

Possibilitou identificar o perfil do mestrando, e partir de suas respostas, relacionar formas de como orientá-lo em relação ao seu projeto e dissertação, além das sinalizações pontuadas para motivá-lo e conhecer sua expectativas, para finalmente então estabelecer a estratégia e metodologia de ensino que melhor atenderá a necessidade do mestrando.

Segue abaixo o quadro demonstrativo com as respostas dos mestrandos, da IESA.

Quadro 2: CURTOGRAMA IES A.

\begin{tabular}{|c|c|c|c|}
\hline CURTO E FAÇO & $\begin{array}{c}\text { CURTO E NÃO } \\
\text { FAÇO }\end{array}$ & $\begin{array}{c}\text { NÃO CURTO E } \\
\text { FAÇO }\end{array}$ & $\begin{array}{c}\text { NÃO CURTO E NÃO } \\
\text { FAÇO }\end{array}$ \\
\hline Aprender coisas novas & $\begin{array}{l}\text { Leitura diversificada e } \\
\text { não faço por falta de }\end{array}$ & $\begin{array}{l}\text { Participar de dinâmica } \\
\text { de grupos com pessoas }\end{array}$ & Não se aplicar ao meu \\
\hline
\end{tabular}




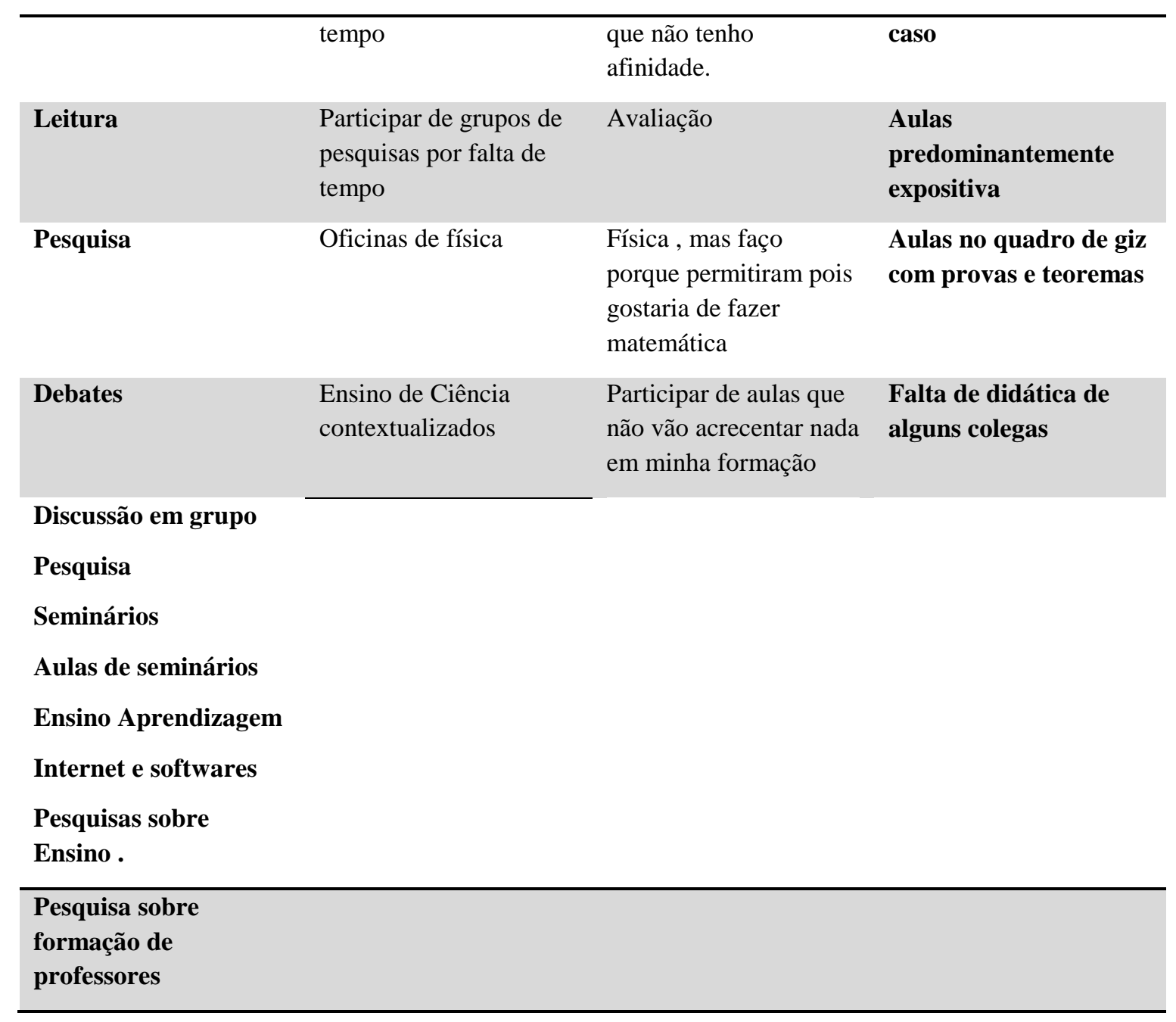

As respostas CURTO E FAÇO demonstradas no quadro acima, apontaram para os gostos e preferências dos mestrados ou seja, eles gostam de aprender coisas novas, leituras debates e pesquisas, discussão em grupos, seminários, pesquisa sobre ensino e pesquisas sobre formação de professores, daí um acertado caminho para o ensino voltado para esta modalidade.

Sinalizaram um grupo voltado para pesquisas, e com um forte interesse por assuntos referentes a formação de professores, participação de seminários, nesse sentido as estratégias de ensino sugeriram os interesses específicos deste grupo.

As respostas CURTO E NÃO FAÇO, foram relacionadas as leitura diversificada devido a por falta de tempo, a participação de grupos de pesquisas, oficinas de física e o ensino de ciência contextualizados. 
Percebeu-se neste item que a falta de tempo foi um dos marcadores predominantes, neste processo, que dificultou a participação efetiva nas atividade que este também gostava de fazer.

Tal percepção sinalizou as diversas atividades que o mestrando vivencia tanto em sua vida profissional, social ou até mesmo acadêmica para conseguir dar conta pelo menos de uma pequena parte no seu desenvolvimento e aprimoramento no mestrado.

Outros itens apontados estiveram relacionados, com a participação de dinâmica de grupos com pessoas que não se tinha afinidade, e a avaliação, e ainda a citação da disciplina de física, que foi citada por uma das mestrandas, onde esta deixou claro que faz, somente porque a permitiram, mas que sua preferência era a opção por matemática, e outra citação foi a participação de aulas que não vão acrescentar nada em sua formação.

As respostas, descritas sugerem apenas uma obrigatoriedade, porém não há vontade ou gosto para o desenvolvimento das atividades apontadas, o que sinalizou não ocorrer o envolvimento ativo do mestrando, este apenas esteve cumprindo uma obrigação, e o processo de ensino e aprendizagem, na verdade não ocorreu tal resposta remete-nos as seguintes respostas: "O professor pensou que ensinou e o mestrando sub-entendeu que aprendeu.

Um outro ponto marcante que também esteve presente nas respostas, foi o da inserção de atividades e ensino, que não contemplava as necessidades de sua formação, levando-os a perda de tempo e o não envolvimento com o ensino oferecido.

Quanto ao NÃO CURTO E NÃO FAÇO, estiveram presentes as seguintes respostas: não se aplica ao meu caso, aulas predominantemente expositiva, aulas no quadro de giz com provas e teoremas, falta de didática de alguns colegas.

Nas respostas apresentadas, o mestrando relacionou suas questões a sua própria auto avaliação, quanto a sua postura docente, suas percepções éticas, sua conduta enquanto profissional, visto que neste item percebeu-se que ninguém faz aquilo que realmente não gosta, pois ninguém deve ser obrigado a fazer, aquilo que não se quer, tratou-se na verdade de uma auto-avaliação.

Segue abaixo o quadro demonstrativo do Curtograma, com as respostas dos mestrandos, do IESB.

\section{Quadro 3: CURTOGRAMA IES B.}

RPI Revista de Pesquisa Interdisciplinar, Cajazeiras, v. 1, Ed. Especial, 444 - 470, set/dez. de 2016. 


\begin{tabular}{|c|c|c|c|}
\hline CURTO E FAÇO & $\begin{array}{l}\text { CURTO E NÃO } \\
\text { FAÇO }\end{array}$ & $\begin{array}{l}\text { NÃO CURTO E } \\
\text { FAÇO }\end{array}$ & $\begin{array}{l}\text { NÃO CURTO E NÃO } \\
\text { FAÇO }\end{array}$ \\
\hline Estudar & Ler & Digitação & Apresentar trabalho. \\
\hline $\begin{array}{l}\text { Leitura relacionada com } \\
\text { minha dissertação }\end{array}$ & $\begin{array}{l}\text { Assistir aulas com } \\
\text { tranquilidade. }\end{array}$ & $\begin{array}{l}\text { Atividades a Curto } \\
\text { prazo. }\end{array}$ & $\begin{array}{l}\text { Atividades não } \\
\text { relacionadas com minha } \\
\text { área de interesse. }\end{array}$ \\
\hline Ir a igreja. & $\begin{array}{l}\text { Aulas relacionadas com } \\
\text { a metodologia. }\end{array}$ & Levantar as 05:30 min. & $\begin{array}{l}\text { Ir a lugar que não gosto } \\
\text { (clubes muito cheio de } \\
\text { pessoas, abafado sem } \\
\text { espaço para andar. }\end{array}$ \\
\hline Ouvir música. & Sem informação. & Trabalhar em grupo. & Assistir jogo de futebol. \\
\hline $\begin{array}{l}\text { Viajar de vez em } \\
\text { quando. }\end{array}$ & Aula de dança & Academia. & $\begin{array}{l}\text { Falar mal (injuriar } \\
\text { pessoas) }\end{array}$ \\
\hline $\begin{array}{l}\text { Encontrar com amigos } \\
\text { em família nos fins de } \\
\text { semana. }\end{array}$ & Aula de outros idiomas. & Plantão. & Destratar os outros. \\
\hline Cantar. & $\begin{array}{l}\text { Leitura de livros que } \\
\text { não sejam relacionados } \\
\text { ao exercício } \\
\text { profissional. }\end{array}$ & $\begin{array}{l}\text { Deslocamento para } \\
\text { estudar. }\end{array}$ & Lecionar sem planejar. \\
\hline $\begin{array}{l}\text { Atividade física } \\
\text { (musculação). }\end{array}$ & Tocar violino. & $\begin{array}{l}\text { Ficar até tarde } \\
\text { acordada. }\end{array}$ & $\begin{array}{l}\text { Dar aula apenas com } \\
\text { recurso de multimídia. }\end{array}$ \\
\hline Trabalho com criança. & Tocar piano. & $\begin{array}{l}\text { Seguir proposta sem } \\
\text { discutí-la em grupo. }\end{array}$ & $\begin{array}{l}\text { Não sei, faço o que } \\
\text { curto e faço o que não } \\
\text { curto por obrigação. }\end{array}$ \\
\hline Tênis (jogo). & Aula de francês. & Obedecer prazos. & $\begin{array}{l}\text { O que não faço, não sei } \\
\text { se curto ou não. }\end{array}$ \\
\hline Ecocardiograma. & Dança de salão. & $\begin{array}{l}\text { Assistir aulas } \\
\text { monôtonas. }\end{array}$ & Arrumar problemas. \\
\hline $\begin{array}{l}\text { Serviço de UTI } \\
\text { neonatal. }\end{array}$ & $\begin{array}{l}\text { Desfile em escola de } \\
\text { samba. }\end{array}$ & $\begin{array}{l}\text { Fazer tabalhos para } \\
\text { cumprir protocolos. }\end{array}$ & $\begin{array}{l}\text { Ser polêmica com os } \\
\text { professores. }\end{array}$ \\
\hline Ler. & Estudar em grupo. & $\begin{array}{l}\text { Disciplinas que nada } \\
\text { acrescentam de } \\
\text { significativo em minha } \\
\text { pesquisa. }\end{array}$ & $\begin{array}{l}\text { Discordar de algumas } \\
\text { atividades propostas. }\end{array}$ \\
\hline Pesquisar. & Planejar. & Trabalhar e estudar & $\begin{array}{l}\text { Atividades sem } \\
\text { objetivos para a minha } \\
\text { caminhada. }\end{array}$ \\
\hline $\begin{array}{l}\text { Aprofundar estudo } \\
\text { inglês. }\end{array}$ & $\begin{array}{l}\text { Projetar com grupos } \\
\text { heterogêneos. }\end{array}$ & Apresentar trabalhos. & Sem informação \\
\hline Leitura Científica. & $\begin{array}{l}\text { Encontrar com os meus } \\
\text { colegas, para momentos } \\
\text { de lazer e descontração. }\end{array}$ & Oficinas. & $\begin{array}{l}\text { Participação em eventos } \\
\text { e oficinas que não tem } \\
\text { aplicabilidade no meu } \\
\text { objeto de estudo. }\end{array}$ \\
\hline $\begin{array}{l}\text { Assistir aulas com os } \\
\text { colegas de turma } \\
\text { (diversidade de áreas). }\end{array}$ & $\begin{array}{l}\text { Final de semana de } \\
\text { descanso. }\end{array}$ & & \\
\hline $\begin{array}{l}\text { Troca de conhecimento } \\
\text { com os professores. }\end{array}$ & $\begin{array}{l}\text { Relaxamento em } \\
\text { família. }\end{array}$ & & \\
\hline $\begin{array}{l}\text { Criação de novos } \\
\text { horizontes para o meu } \\
\text { caminho. }\end{array}$ & $\begin{array}{l}\text { Ter mais tempo para me } \\
\text { dedicar a leitura. }\end{array}$ & & \\
\hline
\end{tabular}

RPI Revista de Pesquisa Interdisciplinar, Cajazeiras, v. 1, Ed. Especial, 444 - 470, set/dez. de 2016. 


\begin{tabular}{|ll|}
\hline Ler artigos. & Atividades práticas. \\
\hline Discutir assuntos. & $\begin{array}{l}\text { Aprimorar } \\
\text { conhecimentos }\end{array}$ \\
\hline Aulas expositivas. & $\begin{array}{l}\text { Aprofundar } \\
\text { conhecimentos basilares } \\
\text { para a educação. }\end{array}$ \\
\hline Palestras. & \\
\hline
\end{tabular}

No quadro apresentado acima o CURTO E FAÇO, foi priorizado por alguns mestrandos quanto as respostas referentes as suas vidas sociais e profissionais suas preferências, e condutas ética, por exemplo: ir a igreja, ouvir música, atividade física, viajar, etc..).

Tal observação sugeriu uma estratégia de enfrentamento, como uma forma de fuga, para não envolverem-se em questões das quais talvez sentissem, a vontade ou com algum tipo de desconforto, para lidarem com estas, ou seja por medo, desconhecimento, preocupação com que outros poderiam pensar a seu respeito, ou uma forma de não se posicionar, pois com a atitude de falar de si mesmo, não colocaria seu posicionamento em destaque, ou por não terem compreendido a dinâmica em si.

Outros, no entanto, descreveram o ato de ler, pesquisar e a menção de aulas expositivas, discussão de assuntos, que sugere este grupo, o gosto por tais estratégias de aprendizagem.

O CURTO E NÃO FAÇO, embora tenha sido citado questões referentes suas preferências individuais e sociais, tais como aula de dança, tocar piano, final de semana com descanso e relaxamento em família.

Foi também citado as preferências voltadas para a leituras relacionadas com a dissertação, aulas de metodologia, estudo em grupo, planejamento, projetos com grupos heterogêneos, maior tempo para a leitura, aprimoramento do conhecimento, e aprofundamento para os conhecimentos de educação relacionado.

Estas respostas, denotaram a expectativa e o desejo de que tais atividades pudessem vir a contemplar o seu processo de ensino aprendizagem e que permitiria a este mestrando atingir o real objetivo de sua inserção no mestrado, profissional.

Estas apontaram para as buscas dos mestrandos para o que realmente gostam e precisam saber e fazer, através das correntes filosóficas e cientificas que permita a problematização e a análise interpretativa que permita a relação entre a teoria e a prática 
NÃO CURTO E FAÇO, fizeram-se presentes através das seguintes atividades a digitação, que para alguns se torna algo que não gostam de realizar, atividades em curto prazo, obedecer prazos trabalhar em grupos, e que podem estar relacionados ao pouco tempo para dedicação ao estudo e atenção a vida profissional, social e familiar.

NÃO CURTO E NÃO FAÇO, destinou-se as respostas relacionadas a atividades do próprio mestrado, entre estas foram citadas as seguintes respostas: atividades que não estejam relacionadas com minha área de interesse e sem objetivos para a caminhada, participação em eventos, demonstrou os mestrandos sinalizaram não gostarem e não fazerem as tarefas apresentadas, foram também descritas as questões referentes a vida social, relacionamentos entre pessoas, profissionais.

Quanto a participação em eventos cabe esclarecer que tal atividade geradas devem estar claras para o mestrando, visto que tem como finalidade, o desenvolvimento das habilidades sociais, cognitivas, investigativa, além de favorecer a integração com a própria aprendizagem e compartilhar métodos de discussão, através da busca de solução para um determinado problema.

Estas respostas apontaram para a direção específica das estratégias de ensino, serem claras, de forma com que os sujeitos envolvidos docentes/mestrandos estejam envolvidos na didática apresentada.

E sempre que possível o professor poderá reformular ou aprofundar em determinado assunto que se faça necessário, a partir das respostas obtidas no Curtograma

Os objetivos que nortearam a aplicação da dinâmica Curtograma foi o de favorecer a reflexão, rever o planejamento e as estratégias de ensino aplicadas na prática pedagógica, ancorados nas teorias das representações sociais, com suas tendências psicossociais e as diversas formas de enfrentamentos vivenciadas pelos mestrandos no Programa de Mestrado Profissional.

Apresentou também a intenção de possibilitar a descoberta de aspectos positivos e negativos, que possam surgir, durante o processo de ensino/ aprendizagem, para possíveis intervenções.

Além de possibilitar a realização do diagnóstico da realidade dos mestrandos bem como o nível de aprendizagem em que estes se encontram e suas dificuldades mais marcantes. 
De modo geral o uso do Inventário de Valoração e Enfrentamento permitiu identificar nas respostas cognitivas e as estratégias que o mestrando utiliza para o enfrentamento e valoração das situações estressantes, diante das mudanças em sua vida.

\section{Conclusão}

O estudo das representações sociais possibilitou um novo olhar para a Psicologia Social, além de enfatizar, outros conceitos e teorias já estabelecidas, e que permitiu a integração com outras áreas de conhecimentos a educação e saúde, possibilitando complementação da pesquisa aqui elaborada.

Alguns problemas foram sinalizados pelos mestrandos entre estes a falta de tempo, que demonstrou, a dificuldade de conciliar o trabalho e estudos, o cansaço físico e mental, as responsabilidades familiares, o contexto familiar que ficou abalado, as responsabilidades junto ao lar, para com os filhos, o cônjuge, além da sobrecarga tripa da jornada de trabalho, necessitando despender maiores esforços para poder cumprir tanto as suas funções regulares de esposa, mãe quanto a de profissional e mestranda, o estresse.

As apresentações orais, o pouco contato com o orientador, as dificuldade na escolha do tema escolhido para a pesquisa, a expectativa de não atingir o resultado esperado pela banca, as cobranças externas para conclusão devido a bolsas, empregos e a solidão na produção de sua pesquisa, entre outros, entre outros

Referentes aos critérios que o mestrando utilizaram a para escolha do Programa de Mestrado profissionalizante, estes apontaram, a acessibilidade, o tempo dispensado para conseguir estar para conciliar os estudos com a vida profissional, além de rever e planejar os horários, para poder então atender as exigências do mestrado, sem no entanto comprometer as relações sociais e familiares e profissionais.

Os mestrandos percebem as políticas para formação dos programas de pós-graduação stricto senso no Programa de Mestrado Profissionalizante, mais simples e mais fácil do que o mestrado acadêmico. Tal resposta sinalizou para uma reavaliação, quanto aos aspectos de sua formação, aperfeiçoamento.

RPI Revista de Pesquisa Interdisciplinar, Cajazeiras, v. 1, Ed. Especial, 444 - 470, set/dez. de 2016. 
Quanto aos apoios que os mestrandos do Programa de Mestrado Profissional recebiam para estarem inseridos no Programa de Mestrado Profissionalizante, o mesmo limitou-se a dispensa de carga horária, isto sugeriu a necessidade de apoio financeiro..

As mudanças que os mestrandos gostariam de realizar no Mestrado Profissional foram o de priorizar as disciplinas no campo de atuação, ter uma seleção criteriosa de mestrandos; inserir disciplinas voltadas para educação e mudanças na prática de ensino e no método de ensino.

As sugestões apresentadas ressaltaram a necessidade de privilegiar os domínios de conteúdo científicos, seus aspectos epistemológicos e históricos de forma contextualizada, explorando suas relações com o contexto social, econômico, político e não somente centrada na transmissão-recepção.

Enfim, para superar as dificuldades dessa formação, os mestrandos e futuros professores devem vivenciar pelo menos duas características. A primeira diz respeito ao pensar holisticamente e interdisciplinarmente para agir transdisciplinarmente.

A pesquisa ofereceu-nos subsídios, para o preenchimento das lacunas existentes na Formação Continuada no Mestrado Profissional, além de identificar as representações sociais, as diversas formas de enfrentamentos e os valores incutidos nos sujeitos pesquisados, através da forma de pensar, interpretar e expressar o seu cotidiano no Mestrado profissional.

\section{REFERÊNCIAS}

ANDRADE, Suely Gregory.Teoria e prática de dinâmica de grupo: jogos e exercícios. Casa do Psicólogo. São Paulo, 2010.

BRASIL. Conselho Nacional de Saúde. Normas de pesquisa envolvendo seres humanos. Res. CNS 196/96. Bioética 4 Suppl:15-25,1996

Ministério da Educação. Câmara do Ensino Superior - C.E.su. Parecer 977/1965, aprovado em 03/13/1065. Define os diferentes tipos de pós-graduação, e informa sobre o contexto histórico e seu desenvolvimento no Brasil e em outros países, além de outras considerações. INFOCAPES. Brasília, v.7, nº 3, out/dez, 1999.

Portaria número 080, da Capes de 16 de dezembro de 1998. Dispões sobre o reconhecimento dos mestrados profissionais e dá outras providências. Unb, Brasília, DF, 1988.

Portaria número 17 da Capes de 28 de dezembro de 2009. Dispõe sobre o mestrado profissional DOU de 29/12/2009 (nº 248, Seção 1, pág. 20).

CAPES, Portaria 080, de 16 de dezembro de 1998. Dispõe sobre o Reconhecimento dos mestrados profissionais e dá outras providências. Diário oficial da República RPI Revista de Pesquisa Interdisciplinar, Cajazeiras, v. 1, Ed. Especial, 444 - 470, set/dez. de 2016. 
federativa do Brasil, Brasília,DF, 11 de jan. 1999. Seção 1,p.14.Disponívelem:http//www.capes.gov.br/export/site/Capes/dowload/Legislação/ Portaria_CAPES_080_1998. doc..Acesso em 02 de set.2011..

DUARTE, Newton. Vigotski e o Aprender a Aprender: Críticas as Apropriações Neoliberais e Pós- Moderna da Teoria Vigotskiana. Campinas São Paulo: Autores Associados, 2001.

FIGUEROA, Nora Leibovich de; SCHUFER, Marta L. et al. El "malestar" y su evaluación en diferentes contextos. Buenos Aires: Eudeba, 2002.

GATTI, A. \& BARRETO. Professores do Brasil: impasses e desafios. Brasília: UNESCO, 2009. 294 p. ISBN: 978-85-7652-108-2

MOSCOVICI, Serge. A Representação Social sobre a Psicanálise. Rio de janeiro: Zahar Editores, 1978.

Ed.:Vozes, 2003

Representações Sociais: investigações em psicologia social. Petrópolis:

NOVIKOFF,C. As Representações Sociais sobre o Ensino Superior de Professores de Graduação da Área da Saúde:Doutorado em Psicologia da Educação.PUC/SP, São Paulo, 2006.

Dimensões Novikoff: um constructo para o ensino-aprendizado da pesquisa. In ROCHA, J.G. e NOVIKOFF, C. (orgs.). Desafios da práxis educacional à promoção humana na contemporaneidade. .Rio de Janeiro: Espalhafato Comunicação, p. 211-242, 2010 .

VALLA, Jorge. MONTEIRO, Maria Benedicta. Psicologia Social. Lisboa: Fundação Calouste Gulbenkian, 2004.

VYGOTSKY. L.S. A Formação Social da Mente. São Paulo: Martins Fontes,1991

RPI Revista de Pesquisa Interdisciplinar, Cajazeiras, v. 1, Ed. Especial, 444 - 470, set/dez. de 2016. 